\title{
The role of GIS technology in determining irrigated geosystems
}

\author{
Oykhumor Ruzikulova ${ }^{1, *}$, Naila Sabitova $^{2}$ and Gulbakhor Kholdorova ${ }^{3}$ \\ ${ }^{1}$ Tashkent Institute of Irrigation and Agricultural Mechanization Engineers, 39 Kari Niyazov str., \\ Tashkent Uzbekistan \\ ${ }^{2}$ National University of Uzbekistan named after Mirzo Ulugbek, 4 University str., Tashkent \\ Uzbekistan \\ ${ }^{3}$ Jizzakh state pedagogical Institute named after A. Qodiriy, Sharaf Rashidov prospect 4, Jizzakh city, \\ Uzbekistan
}

\begin{abstract}
Irrigated lands of Bukhara, Samarkand and Navoi regions are located in the Zarafshan river oasis and are called geosystems. Assessment of the reclamation state of geosystems of the region has been carried out in the area of classification and mapping for the effective use of land. When classifying a research object, it is much easier to identify, evaluate and apply reclamation measures. In the classification of landscapes, they are grouped in a certain order and there is an opportunity to apply such reclamation measures. So far, the basin-level classification of the Zarafshan river oasis and geosystems has not been carried out. In the scientific paper, landscapes were analysed as a form of geosystem. The geosystems of the region were grouped and summarized for the performance of the reclamation geographical assessment based on water and salt parameters. The classification of the object of study using GIS is of great scientific and practical importance. An analysis of the origin, structure, development and other features of an object when it is classified will determine the scientific significance of the case. Geosystems were isolated using the forms depicted on the relief plastic card in the scientific paper. Measures have been developed to improve the reclamation state of existing geosystems. They reached scientifically sound conclusions. Keywords: Plastic method of relief, flow patterns lithodynamics, melioration, salinization, landscape, groundwater and surface water, assessment of melioration, mapping.
\end{abstract}

\section{Introduction}

Actuality of the topic. State reforms implemented in Uzbekistan in recent years cover all sectors of agriculture, among other areas. It is known that the amount of irrigated land and inland water in Uzbekistan is limited. Therefore, the use of GIS in classifying and evaluating the ameliorative status of geosystems of the oasis is considered as a solution to existing problems. Object of research: Irrigated lands of Samarkand, Navoi and Bukhara regions, geosystems of the oasis. In the context of natural population growth in Uzbekistan,

* Corresponding author: oyhumor.ruzikulova@gmail.com 
the issue of rational use of resources is still relevant. This research work is based on the Decree of the President of the Republic of Uzbekistan dated October 23, 2019 No PF-5853 "On approval of the Strategy of agricultural development of the Republic of Uzbekistan for 2020-2030", as well as land and to some extent serve the objectives set out in other regulations on the efficient use of water resources. Moreover, the classification of any geosystems on the surface using morphometric analysis of horizontal lines on topographic maps ensures efficient use of the land.

Geosystems are defined as their stability, their resistance to various external influences. Geosystems differ from the second geosystem by mechanical composition, basic physicochemical properties of soil, water and other parameters. The hydrographic net is well represented in these areas. Therefore, the boundaries of geosystems are important for their formation, stratification and development. In turn, separation and classification of boundaries of geosystems will help to define separate meliorative-geographical measures in each element. At present, there is no consensus on the geosystem boundaries on the regional and typological orientation maps. Even on maps drawn directly in the field, the boundary is crossed, depending on the knowledge and skills of the landscape scientist.

From the literature analysis, it was found that the most convenient way to limit geosystems was mapping techniques relief plastic. Relay plastic is a description of the sequence of altitudes and lows in nature. One of the key issues in land reclamation is the disclosure of reasons for spatial development of processes within the boundaries, quality and quantity changes. In the determination and evaluation of the reclamation state of small geosystems, the upper, middle and lower parts of the geosystems were allocated. In geosystems, areas of salinity occurrence, movement and accumulation of salts are highlighted. It is important to put these places clearly on large-scale maps.

One of the key issues in land reclamation is the disclosure of reasons for spatial development of processes within boundaries, quality and quantity changes. In the determination and evaluation of the reclamation state of small geosystems, the upper, middle and lower parts of the geosystems were presented. In geosystems, areas of salinity occurrence, movement and accumulation of salts are highlighted. It is important to put these places clearly on large-scale maps.

These geomorphological forms represent the locations of formation, movement and accumulation of salts in soils. For example, the elongated forms on the relief plastic card indicate the locations of the salts, and the triangular shaped forms indicate the locations of the salts.

Regional geosystem at work; natural boundary - subsystem; facies-studied as elements of the system. The accumulation of salts in the soil is mainly dependent on the following local natural conditions: relief and geological structure of the area, climate, soil-water permeability properties and so on. Depending on the rate of flow of the Zarafshan river and the mechanical composition of the river bed, the rock brings sandy, sandy, sandy and other deposits. In the selection of streams, large boulders, gravels, and then smaller sandy and sandy rocks, then sludge and sediments are selected.

According to [1] saline soils are the soils with a total content of easily soluble salts, accumulating more than $0.25 \%$ of the soil weight and preventing or cultivating cultural plants. Dynamic transformation of salts in soils of the region's geosystems is also influenced by the principles of stratification of geosystems. Of these salts the specificity of salts plays an important role in land reclamation.

Leading soil scientist and land reclamation [24, 3] show that salt flowing in water is based on the following law.

Carbonate salts are more water-soluble than sulphate and chloride salts. Chlorine salts, on the other hand, are difficult to dissolve in water. Surface water (spring, stream, small and large rivers) in the oasis and the chemical composition of the oceans provide information 
on the chemical composition of the water-soluble substances of the soils. Many scientists have already noted that the chemical condition of the soil cover of irrigated lands can be determined by the rivers and lakes flowing through it. One of the causes of salt accumulation and secondary salinization in the soils is also determined by the composition of the rocks in the river bed.

\section{Study area}

In particular, according to the geomorphological condition of the valley of Zarafshan (Uzbekistan) (Fig.1) owing to the geomorphological features of AN Hodzhimatov. The oasis is divided into delta plains, alluvial terraces, proluvial plains, lowlands, cones, slopes, plateaus and hills. Delta Plains: head, middle and periphery; alluvial terraces, respectively: to the lower (I and II) and to the upper terraces (III and IV); the middle and main parts of the proluvial plains and surrounding (peripheral) parts; lowlands; cone spreads on the head, middle and surrounding parts; hills to slopes; plateau and hills are subdivided into lowlands $[32,23]$. Studying the chemical composition of water entering lakes and reservoirs in the Zarafshan river basin will help to identify and re-climate the reclamation state of the soils in the basin. All river basins have areas of formation, movement and accumulation of matter and energy. Part of the formation is caused by atmospheric precipitation and constant flow of surface and groundwater from rocks. There is a transformation of surface and groundwater at the places of movement. At the site of accumulation, salts come from solid and organic matter and accumulate in the bottom and in the sediments of geosystems. This causes soil salinity. Soil and geochemical conditions of the river basin require the use of agrotechnical measures for land reclamation. The extensive involvement of the region's geosystems in irrigated agriculture has led to profound changes.

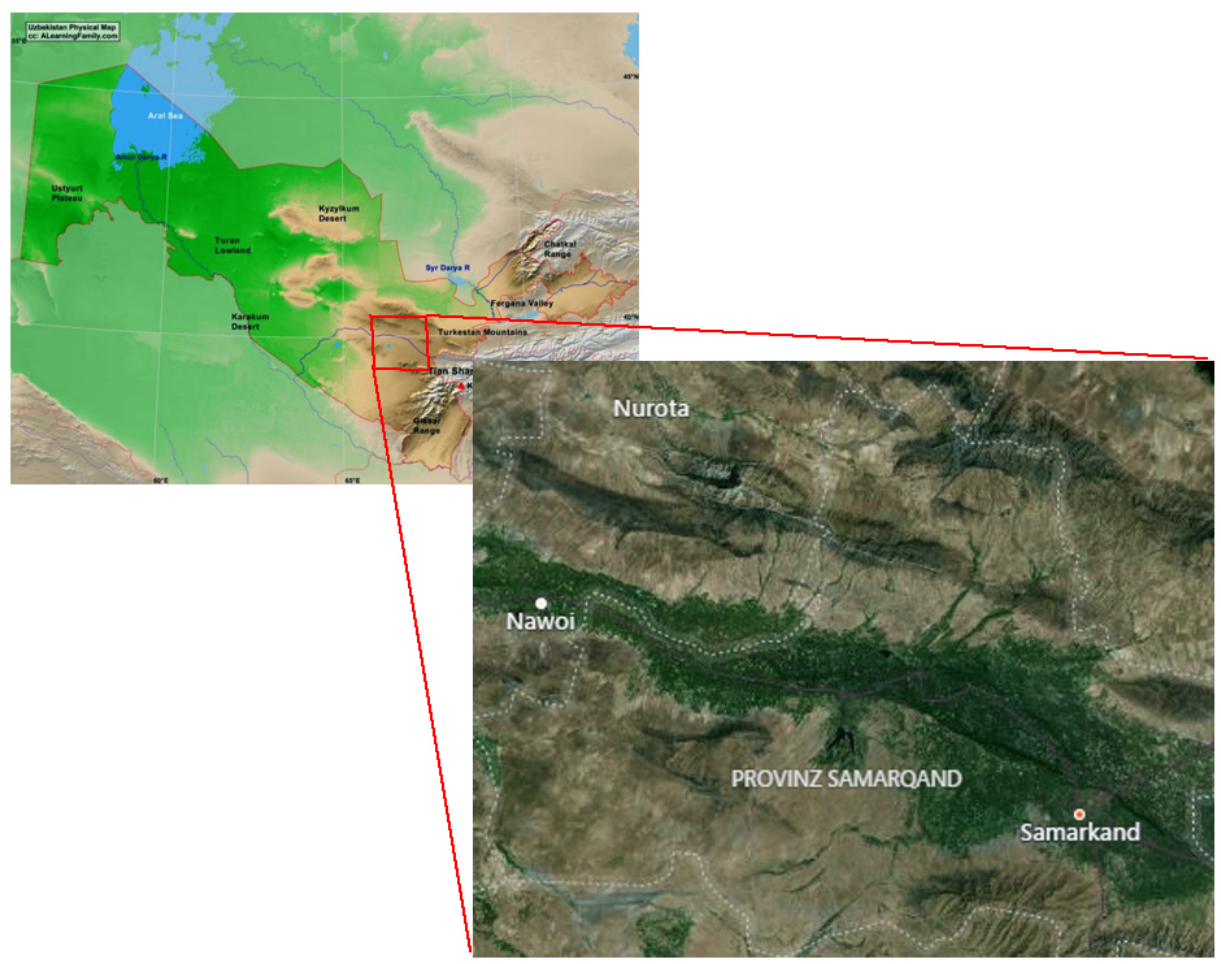

Fig.1. Middle Zarafshan river (Zarafshan valley) (Source: https://www.mapsofworld.com/uzbekistan/ and bing map) 


\section{Methods}

Sochava in his scientific work developed [6] the scientific basis for the stabilization and efficient use of the natural environment [27, 31,9]. Geosystems are subdivided into planetary (geographical), regional (natural geographic zones, large countries, provinces and landscapes), and topological (structural, morphological parts of landscapes: place, urochishche, facies).

The concept of geosystems contributes to the development of modern areas of natural geography. It has been a ground for new approaches in science that have made it possible to apply the results.

The classification indicators developed by [10] are remarkable for their scientific accuracy and convenience. Therefore, the classification was used in scientific work $[10,8$, $14]$. In classification of geosystems in the middle and lower reaches of the river, $[6,15,23]$. It was based on landscapes isolated [9].

The classification of geosystems used a method of relief plasticity. This method is based on scientific research $[16,17,22]$ and others have done research. This method was first used for the reclamation of the northern Mughan and southeastern Shirvan plains (19391940) [7].

The method of relief plastics was used by [34] in his work. The top and bottom of the aquifers, which are the main elements of relief, are depicted as a line along the relief slope [31]. The relief plastic card clearly separates the boundaries of the on-site reservoirs. The advantages of using this method in meliorative-geographical research have been described in the work $[29,8]$. The water-salt parameters of river basin geosystems change with the occurrence of natural effects of melioration in the river basin: hydrological, hydrogeological, lithological, soil, etc.

The quality of river water in the oasis is subdivided into 2 classes:

1) Closed geochemical, inactive, that is, salts move through low water flow (low irrigation).

2) Open geochemical, active - movement of water-soluble salts, rapid migration (excessive irrigation, leaching, mainly drainage activities). The basin method should also take into account the accumulation of salt in the soil and its spatial distribution.

The methods used to create a relief plastic card were used. The altitude and altitude were determined by baseline equations of the earth surface based on a 1: 100,000 scale topographic map of the study $[16,25,13]$. On this map, geosystems represent the basins formed by surface and groundwater flows. Their geomorphological forms served as an important criterion for delineation and classification of boundaries (Fig 2). The maps of this scale show their location on the map [13-15].

\section{Results}

In the classification of geosystems, their morphotectonic features were taken into account, and the classification of mountain and plane geosystems was separated. The main difference between them is based on the fact that natural zones are represented in two types (plains - horizontal, mountains vertically) (table). Subclasses are distinguished according to the geosystems development. Mountains - to moderate and low mountains; Plains - divided into high, moderate and low plains.

Relative altitudes up to $700-800 \mathrm{~m}$ are precipitated, mountains below 1000-1500 m, and uplands with 2000-2500 m are referred to as moderate mountains (up to 4,000 $\mathrm{m}$ in wet tropics) $[10,8,14]$. The elevation rises, climatic zones change, and the formation of a zircon as a change of the vertical zonal regularity is equally important. Upper, middle and low mountains of medium height in the Zarafshan river basin; high plains (plateaus and 
hills), plains of moderate height (proluvial and deluvial plains and alluvial plains), low plains (terraces I and II) and others. Mountain geosystems by their suitability are divided into 3 groups: high, middle and low mountains of medium height. There are no high mountains (above 2000-3000m) at the study site. Geosystems from the average altitude mountains: Chakilkalon, Karatepa, North Nurata, Koratov and Aktov were classified.The classification of geosystems is based on similar features (table 1).

Table 1. Classification of Zarafshan river basin geosystems

\begin{tabular}{|c|c|c|c|}
\hline $\begin{array}{l}\text { classification } \\
\text { units }\end{array}$ & $\begin{array}{l}\text { definition of classification } \\
\text { units }\end{array}$ & \multicolumn{2}{|c|}{ examples of classification units } \\
\hline \multirow{2}{*}{ class } & \multirow{2}{*}{$\begin{array}{l}\text { morphotectonic properties } \\
\text { and diversity of natural zones }\end{array}$} & \multicolumn{2}{|l|}{ mountains } \\
\hline & & \multicolumn{2}{|l|}{ landscape } \\
\hline \multirow{2}{*}{$\begin{array}{l}\text { small } \\
\text { class }\end{array}$} & \multirow{2}{*}{$\begin{array}{l}\text { formation of geosystems } \\
\text { (step) } \\
\text { formed). }\end{array}$} & mountains & $\begin{array}{l}\text { 1.middle high mountains } \\
\text { 2. lower mountains }\end{array}$ \\
\hline & & landscape & $\begin{array}{l}\text { 1. high plains } \\
\text { 2. plains of medium height } \\
\text { 3. low plains }\end{array}$ \\
\hline group & $\begin{array}{l}\text { wet, water and geochemical } \\
\text { properties }\end{array}$ & \multicolumn{2}{|c|}{$\begin{array}{l}\text { automorf half } \\
\text { hydromorph hydromorph }\end{array}$} \\
\hline type & zonal and bio-climatic signs & \multicolumn{2}{|c|}{ mountain, highlands, desert } \\
\hline \multirow[t]{2}{*}{ middle type } & \multirow[t]{2}{*}{$\begin{array}{l}\text { according to the small zonal } \\
\text { signs }\end{array}$} & \multicolumn{2}{|c|}{$\begin{array}{l}\text { 1. a) upper mountains of medium height, b) } \\
\text { middle part, c) lower part }\end{array}$} \\
\hline & & \multicolumn{2}{|c|}{ 2. on the plains: high hill, lower hill } \\
\hline classification & $\begin{array}{l}\text { geological and } \\
\text { geomorphological types }\end{array}$ & \multicolumn{2}{|c|}{ denudation, erosion, accumulation } \\
\hline sorts & $\begin{array}{l}\text { relativity and resemblance of } \\
\text { relef in geosystems }\end{array}$ & \multicolumn{2}{|c|}{$\begin{array}{l}\text { a) water environment } \\
\text { b) private disabilities } \\
\text { c) tepalities } \\
\text { d) terrases } \\
\text { e) the beggars }\end{array}$} \\
\hline
\end{tabular}

The lower reaches of the mountains include Karakchitov, Gubdintov, Gallaorol, and Ziyovuddin-Zirabulak geosystems on the left bank. High Plains Passarghom, Ulus; MidPlains Plains Aktash, Malikchul and Karnobchul and Low Plains Alluvial valleys of Zarafshan river basin: Samarkand, Kattakurgan geosystems; erosion-tectonic swamps (Dengizkul lake, Oyagogitma, etc.); hills (Jarkoq, Saritosh, Balandkum, Khamza, Dengizkul, Gazli, Chaponota, etc.), alluvial-delta plains, and sub-classes of geosystems of the region are included.

Geosystems grouped according to their water-geochemical properties, namely moisture. The basis of zonal and bio-climatic features of the separation of geosystems was laid. The subspecies were classified on the basis of small zonal signs, categorizing geosystems according to geological and geomorphological features (denudation, erosion, accumulation). The study considered the types of relief, the lithological composition of the rocks that make up the geosystems.

Types of geosystems are units of individual geosystems that have the same origin and internal structure. They are distinguished by the dominant females in the geosystem, along with their morphological structure (slope of relief). An example is the Miyangal geosystem, covered by typical clay soils in the alluvial valley (Fig. 2 and Table1).

The classification of geosystems of Samarkand, Kattakurgan, Navoi-Konimeh, Bukhara and Karakul oasis was as follows. Zarafshan River Basin is a unique region in terms of meliorative conditions of the oasis geosystems. The geosystems of the oasis are subdivided into sub-classes of alluvial plains of terraces of the plain, the plains of the Zarafshan River 
and slopes, and alluvial-delta plains. The most important feature of Oasis geosystems is that they extend from east to west. The basin has a moderate continental climate. The border between them crosses the Hazora corridor. Key Climate Differences explained by Kogay and Babushkin [5].

Changes in a certain boundary of the components that make up the geosystem are based on geographic patterns. When considering the principles of stratification of geosystems, it is appropriate to mention the relief plastic card of the research object (Fig 2). In the course of the research, the map of relief plasticity of the Zarafshan river basin geosystems was compiled using the topographic mapping equations of scale 1:50000 and 1: 100000.

Geosystems grouped on the basis of their moisture content and dynamic movement of groundwater. According to it, hydromorphic geosystems in the basins of the region are located 1-3 meters above ground surface, and automorphic geosystems in the areas below $3 \mathrm{~m}$.

The category of geosystems - is grouped by species based on the geological and geomorphological conditions, the genetic types and the geological structure of the relief. They were classified as alluvial plains, deluvial and proluvial plains, a number of sand dunes and more.

The categories of geosystems are divided into species. The landscape species are classified on the basis of the similarity of the most common dominant species in geosystems. The mountainous part of the basin is named after the geological rocks of the earth. For example: limestone-covered karst caves; in the desert, psammofit bushes with sandy soils and so on.

The following principles (principles) are used in conducting the land-reclamation and geographical assessment of soil salinization in the geosystems of the Zarafshan river basin.

1. Genetic (formation and development of geosystems).

2. Combining both zonal and azonal factors.

3. Dynamics (dynamic transformation of salts in geosystems soils and movement of matter and energy within a certain boundary).

4. Symmetry. Each geographic unit on the surface is symmetric or asymmetrical in its shape. These features also influence the stratification of geosystems.

The genetic principle of stratification of geosystems of the oasis is related to their geological history. Most of the oasis of Samarkand, Kattakurgan, Navoi-Konimeh, Bukhara and Karakul have been affected by different geological periods, as well as by differentiation of geosystems in the oasis. The mountains surrounding Samarkand and Kattakurgan oasis are also rich in various chemical elements. Under the influence of atmospheric precipitation and water, these minerals also melt and accumulate in the low-density geosystems of the geosystems by surface water.

The principle of combining the zonal and azonicity factors was followed by a systematic analysis of functional integrity in order to determine the reclamation state of the geosystems of the oasis.

There is a transformation of salts corresponding to the geographical location of the oasis geosystems. These dynamics indicates the distribution of salts in the soil on the basis of certain regularities. Hydrocarbon salts are first found along the river, followed by sulphate and chloride salts.

Most rivers on the right and left sides of the river are symmetric. This enables data to be transferred from one to another and used in a different geosystem. This is based on the relative homogeneity of geometric structures. Rectangular shapes are considered to be the most symmetric state in nature. The triangular shapes in the delta represent the accumulation of matter. The limestone forms are abundant along the river, and the river water does not exert too much effort on their formation (basin relief plastic card). 
Cartographic techniques play an important role in describing the formation, development and stratification of geosystems of the region. The spatial features of the spatial development of the functional changes of geosystems are illustrated using the cartographic method. Geosystem mapping techniques are implemented in a variety of ways.

As you know, the cards are divided into general geographical and special thematic cards. and others have mentioned the diversity of geographic maps and their classification for different purposes $[26,33]$. When dividing geographic maps into groups, they are based on the space they are describing, the purpose, content, scale and other features of the card. Topographic maps are used as a basis for drawing up geographical maps. General issues such as the mathematical basis of the card developed in the cartography, mapping, analysis, and printing are also first of all topographical [6]. The features, contents and methods of using modern topographic maps are quite complex. Modern computer technologies are used to create and use cards.

On the left bank of the Zarafshan River, mountainous geosystems are represented by mountains of average altitude (Chakilkalon and Karatepa), low mountains (Ziyovuddin and Zirabulak) and lowland plains with low plains (Pasdargom, Kokdala, Ulus). The geosystem class, subclass, group, type, type, sub-type, category, type was isolated in the plains of the valley and separately evaluated (table 1). Classes of geosystems of plains, steppes, hills, foothills, alluvial delta and ancient delta plains geosystems class, subclass, group, type, subgroup, category, type were analyzed separately.

The present irrigated part of the Zarafshan river basin consists of alpine, first and second shelf terraces, mountain slopes, right and left coastal deluvial and proluvial plains, and terraces of the third.

Surface lithology has been studied as a key factor in determining the boundaries of geosystems of the Zarafshan River Basin. The lithogenic basis is the geological, lithological and surface relief forms. The lithogenic basis has been studied as a key factor in the work.

To separate the boundaries of the geosystems of the studied area, the relief was taken as a landscape-forming factor. The boundaries of the geosystems are passed through the aquifers of surface and groundwater basins, which differ in their geochemical changes and geophysical features [16].

The third shelf terrace is separated by steep slopes from the alluvial valley. There are deluvial and proluvial plains between the third terrace and the mountain. Its width extends up to $15 \mathrm{~km}$ on the right bank and $8 \mathrm{~km}$ on the left. Most of the second terrace is on the island of Miyangol. It consists of alluvial pebbles and loamy sands, and up to $5 \mathrm{~m}$ in some places. The first reverse plane occupies the entire area of the Zarafshan river on the right bank, 0.2-1.8 km east of Samarkand. On the right bank of the Black Sea, it is difficult to distinguish the boundary of the Terrace II.

The Zarafshan river basin has a clear natural boundary and can be divided into 3 cascade systems (upper, middle and lower) on a 1: 100,000 scale relief plastic card. They are important in assessing the ameliorative status of oasis geosystems. Studies of the research object as cascading systems are available in published work. The middle part of the Zarafshan river basin has a "long onion" shape on the relief plastic card. This form plays an important role in land reclamation. The direction of flow has arisen and evolved depending on the forms of relief. Hydrodynamic processes with different geochemical and geophysical features complicate the water-salt properties.

The change of water-salt parameters of geosystems soils over time and space was analyzed. The map distinguishes mountain and plane geosystems, and their different geosystems are classified. On the basis of field researches and published literature reclamation geographical assessment was carried out. The criteria used were the geosystems 'salts' quality characteristics, the amount of gypsum, the salts of light salts and the surface water and mineral content. 
Saline areas of Bulungur (I) hydrocarbonate (II), sulfate (II) in Kattakurgan and chlorine (III) type in Karakul were identified as salt deposits. Recommendations were developed within the framework of scientific research.

Our recommendations are aimed at establishing a scheme for assimilating various parts of geosystems for farming purposes (Fig. 2).
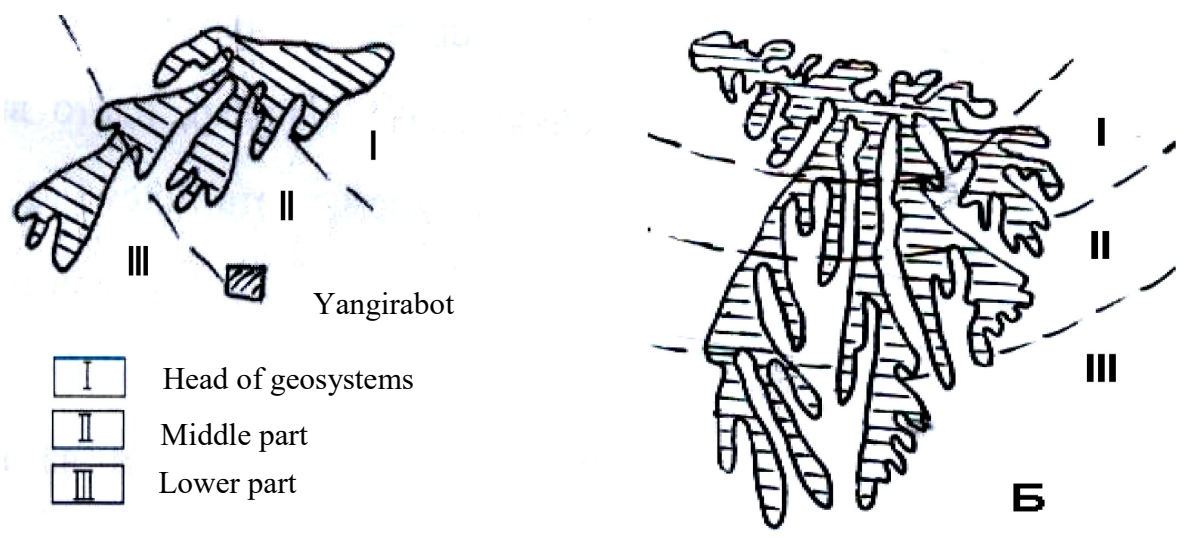

Fig. 2. Scheme of land development (A - alluvial plains, B - as an example of deluvial and proluvial plains on mountain slopes).

Stabilization and improvement of reclamation conditions in the middle and lower parts of the Zarafshan River Basin will ensure the efficient use of existing land resources. As a result of the research, the following scientific and practical recommendations for the reduction and classification of saline lands have been developed.

1. In the first phase of the study of the reclamation situation in the geosystems of the region, topographic maps and aerial photographs should be analysed in a natural geographical manner. The natural geographical conditions of the region's geosystems and the economic activities of people should be studied using a systematic approach within large and small ponds.

2. When applying a systematic approach, the horizontal horizontal and large-scale topographic maps are analysed using the Release plastic method. Topographic maps create images of streams formed by ground and surface water. It is recommended to limit the geosystems using the relief plastic card and to separate the upper, middle and lower parts of the geosystems.

3. From the geosystems isolated using the relief plastic card, the base points (areas) for field research will be identified. It is desirable to determine the reclamation state by analysing the chemical composition of groundwater and surface water salts in the soil layers of these regions.

4. The use of geosystems based on relief plastics can be cost-effective in designing irrigation systems and implementing reclamation measures. In the alluvial plains, the main part of the geosystem should be developed first, the second part II and the third part III (Fig.2 A). In the geosystems of the deluvial and proluvial plains on the mountain slopes, the initial part I (Fig.2, B) is first developed. After that it is necessary to master the middle part II and finally the third part. This is because lithodynamic flow caused by the natural movement of groundwater and surface water moves from top to bottom. As a result, soil salts accumulate in the lower parts of geosystems. Our recommendations are aimed at establishing a scheme for developing different parts of geosystems for farming.

5. In designing of collector and drainage networks, it is necessary to thoroughly analyse the surface relief forms. It is desirable to design a land reclamation network based on a 
relief plastic card that accurately describes groundwater and surface water flow (Fig.2). On this card, meso - and microrelefe shapes - allow the deposition of salts and water dissolved in the soil as a "flow". The direction of surface and ground water flow from the bubbles to the lowlands is clearly visible. Existing collectors and streams through these lowlands will improve land reclamation.

\section{Conclusion}

As a result of the research, the following conclusions were made:

1. It is desirable to carry out studies using the basin method of systematic analysis to assess and classify the reclamation state of geosystems of the oasis by salinity of soils. This was based on the creation of relief plastic cards by analyzing the horizontals of topographical maps of the mid-scale.

2. The choice of base points (areas) for field surveys using relief plastic cards is justified. This method describes the possibility of separation of geosystems soils in areas of changes in the quantity and quality of dissolved salts. Field studies were conducted in the spring and fall seasons, with strong changes in surface and surface water and chemical composition.

3.The basins formed by the flow of groundwater and surface water have been taken as geosystems. Their frontiers were passed through waterfalls in the mountains and geophysical and geochemically altered areas of the surface of the plains. The hydrographic net is well represented here and there is a significant change in soil salinity and salinity.

4. It is desirable to carry out their classification to identify and assess the reclamation state of large geosystems.

5. The scheme of land use was developed on the basis of the classification of geosystems of the region.

\section{Reference}

1. R. Abdullaev, J. P. Sattorov, Problems of using land resources and their solutions. Problems of organization of land resources use and land cadastre. Collection of articles of the Republican scientific-practical conference. (2005)

2. A. U. Akhmedov, P. A. Abdullaev, N. I. Sabitova, G. T. Parpiev, Problems of salinization, land reclamation and soil fertility. Actual problems of soil science (2004)

3. A. U. Ahmedov, G. T. Parpiev, O. Sh. Ruzikulova, Evaluation of soil-reclamation condition of stationary-ecological sites of Syrdarya region. New technologies for increasing soil fertility: Proc. of the Inter. Con. (2004)

4. L. N. Babushkin, N. A. Kogay, Physico-geographical district Uzbekirovoy SSR. Trudy TashGU. (1964)

5. L. N. Babushkin, N. A. Kogay, Modern methods of operation of the prirodx method for the selskogo xozystva, Questions of geography (1975)

6. A. M. Berlyant, Cartography. (2002)

7. V. R. Volobuev, Kura-Arakinskoye map of the Kura-Arakinskoye district. Pochvovedenie, (1987)

8. V. A. Nikolayev, Level landscape, Theory and methodology. West. Geography.. No. 4, (2006)

9. V. P. Preobrajensky, Problems of the evolution of geosystems. Nauka, (1983)

10. A. Yu. Retayum, Physico-geographical zoning and the geosystem. Vopr. geogr. (1975) 
11. O. Sh. Ruzikulova, Ways to improve the methods of soil-reclamation map of Zarafshan oasis. Proceedings of the Fourth Congress of Soil Scientists and Agrochemists of Uzbekistan. (2005).

12. O. Sh. Ruzikulova, Geographic bases of salinization. Role of women in science and technology development: Proceedings of the Republican scientific-practical conference. (2008)

13. N. I. Sabitova, Application of the relief plastic method to geomorphological zoning using the example of the eastern part of the Zarafshan river valley. Journal of geology of Uzbeksitan. №4 (1990)

14. N. I. Sabitova, Scientific foundations of the morphohydrogeometric method in solving geo-hydrogeological problems (for example, Uzbekistan and adjacent territories): Dir Doct. geographer. sciences. (2002)

15. N. I. Sabitova, O. S. Ruzikulova, Reclamation assessment of soils in the middle and lower parts of the Zarafshan river valley within the established boundaries of geosystems. Actual problems of natural and economic geographical zoning: Proceedings of the Republican scientific-practical conference. (2004)

16. N. I. Sabitova, A. U. Akhmedov, G. T. Parpiev, O. Sh. Ruzikulova, The geometric feature of the morphological structure and the water-salt regime of the middle and lower parts of the valley of the Zarafshan River. New technologies for increasing soil fertility: Proceedings of the International Conference. (2004)

17. N. I. Sabitova, A. U. Akmedov, System analysis in the study of the reclamation state of soils (On the example of the Zarafshan river basin). Mat. IV congress of soil scientists and agricultural chemists of Uzbekistan. (2005)

18. N. I. Sabitova, O. Sh. Ruzikulova, Geosystems of the Zarafshan river basin and their soil-reclamation properties. Proceedings of the International Scientific Conference. (2006)

19. N. I. Sabitova, A. U. Akhmedov, O. Sh. Ruzikulova, G. T. Parpiev, The image of stream structures in the soil-reclamation map. Agricultural science - to agriculture: International scientific and practical conference. (2006)

20. N. I. Sabitova, U. K. Abdunazarov, O. S. Ruziqulova, The role of topographic maps in identifying the formation of streaming geosystems on the earth's surface of the Zarafshan River valley. Actual problems of Geography Conference.(2006)

21. N. I. Sabitova, O. Sh. Ruziqulova, Soil-reclamation map of the Zarafshan Valley. Materials of the VII Congress of the Geographical Society of Uzbekistan. (2006)

22. N. I. Sabitova, O. Sh. Ruziqulova, Oasis geosystemalining reclamation Kolati (Zarafshon Daro Kawzashi Misolid). Journal Society of Geograpy of Uzbekistan 29 (2007)

23. K. A. Salishchev, Cartography. Publication of Moscow State University, (1982)

24. V. V. Sochava, Introduction to the doctrine of geosystems. Nauka, (1978)

25. I. N. Stepanov, N. I. Sabitova, E. I. Chembarisov, Some principles of building a galeogeochemical map of reclaimed territories. Assessment of natural reclamation conditions and forecast of their changes (on the example of Central Asia). Materials of the All-Union Conference. (1977)

26. I. N. Stepanov, E.I. Chembarisov, The effect of irrigation on the mineralization of river waters. Nauka (1978)

27. I. N. Stepanov, Space and time is soil science. Nedokuchaev soil science. Nauka (2003) 
28. V. P. Philosophers, Fundamentals of the morphometric method of searching for tectonic structures. Publishing House - Sarat. University (1975)

29. A. N. Khozhimatov, Oasis landscapes of the desert zone of Uzbekistan: state, assessment and forecast of possible changes (for example, agricultural systems of the lower reaches of Zarafshan and Amu Darya): Author. DiP Cand. geographer. sciences. (1996)

30. A. Egamberdiev. Formation, current status, problems and prospects of cartography in Uzbekistan. University (2001)

31. Li Xia, W. McCarty, Gregory, Application of Topographic Analyses for Mapping Spatial Patterns of Soil Properties, Earth Observation and Geospatial Analyses https://doi.org/10.5772/intechopen.86109 (2019)

32. C. C. Paz, T. R. Teresa, Factors of Soil Formation. Encyclopedia of Earth Sciences Series https://doi.org/10.1007/978-1-4020-3995-9_207 (2008) 